\title{
Active Learning Strategies and Instructor Presence in an Online Research Methods Course: Can we Decrease Anxiety and Increase Perceived Knowledge?
}

\author{
Lisa Rapp \\ Victoria Anyikwa
}

\begin{abstract}
Research methods courses elicit more anxiety than usual for graduate social work students, and the online environment may pose an even greater challenge as the personal interaction between instructor and student is reduced or absent. It is therefore incumbent on research instructors to creatively engage students, reduce anxiety, and foster learning. There is a dearth of evidence, particularly regarding online education, explicating specific teaching strategies. This exploratory study sought to provide some answers. First-semester MSW students were invited to participate in a voluntary, anonymous, online survey at the end of a research methods course to determine which online teaching strategies were most effective in decreasing anxiety and increasing perception of knowledge. Strategies used in the class include asynchronous activities such as discussion questions, PowerPoint lectures, and email and telephone contact with instructors in addition to synchronous class sessions. Three tactics were rated by the 43 respondents as being most helpful for both decreasing anxiety and enhancing the perception of knowledge: personal contact with the instructor either via email, phone, and/or online meetings; the instructor's synchronous class sessions; and active learning strategies employed during the synchronous class sessions. Implications for teaching and future research are discussed.
\end{abstract}

Keywords: Teaching strategies; active learning; instructor presence; online learning; anxiety reduction

Online learning in higher education has proliferated in recent years resulting in the adaptation of courses from traditional to online formats without much consideration for the course content or learning process (Tsai, 2012). A study by Castaño-Muñoz, Duart, and Sancho-Vinuesa (2014) noted that to encourage student learning, cooperative and interactive learning strategies which are effective in face-to-face courses must also be incorporated in online courses. Likewise, Xu and Jaggars (2014) found that students generally view online courses as isolating and lacking in instructor presence. In these courses, students feel that they must teach themselves. Consequently, most students report trying to avoid taking "difficult" or "important" courses online.

Besides a delivery barrier, some courses pose more challenges than others for the online environment of students. In graduate-level social work programs, the research methods course is often a concern in both traditional and online formats. This is a difficult course requiring students to learn a vast amount of new knowledge and skills in a short time frame. In addition, the students in graduate social work programs come from a wide variety of undergraduate majors and backgrounds, and many have never been exposed to the terms and concepts of research.

Lisa Rapp, PhD, MSW, Professor, Graduate Social Work program, Saint Leo University, Saint Leo, FL 33574-6665.

Victoria Anyikwa, PhD, LCSW, Associate Professor, Graduate Social Work program, Saint Leo University, Saint Leo, FL 33574-6665. 
The situation is exacerbated by the students' attitudes towards research, which have been reported as disinterested, irrelevant, bored, and annoyed (Lundahl, 2008; Schulze, 2009). Studies have noted that research courses also provoke anxiety in students (DeVaney, 2010; Green, Bretzin, Leininger, \& Stauffer, 2001). Green et al. (2001) compared research anxiety across various disciplines and found MSW students had higher anxiety than their counterparts regarding research methods and analysis.

Student anxiety is a serious concern in the learning environment as it has been found to have a negative relationship to learning outcomes (Jiao, Onwuegbuzie, \& Waytowich, 2008). Chan and Lee (2005) noted that student anxiety creates a barrier to learning, and Ramsden (1992) found it affects learning styles and can inhibit deep learning. While Gal and Ginsberg (1993) suggest students' preconceived ideas about the subject are the root cause of anxiety, this was found most frequently for math, statistics, and science courses. As such, research methods delivered in an online environment may be experienced as even more daunting than traditional formats, making the use of effective teaching strategies critical.

\section{Active Learning Pedagogical Approach}

Active learning strategies have been found to be very effective in traditional classrooms (Bonwell \& Eison, 1991; Freeman et al., 2014). Active learning strategies are based on earlier constructivism theories that are rooted in the works of psychologists Jean Piaget, who focused on individuals' cognitive development processes (Lefmann \& CombsOrme, 2013), and Lev Vygotsky, who focused on socio-cultural learning and meaning making through social interaction, problem-solving, peer facilitation, and questioning (Jaramillo, 1996). Constructivism learning theories posit that individuals learn through cognitive processes, thereby building and creating their own understanding and knowledge of a phenomenon based on experiences, and through social constructivism, learning from each other and building on their own cognitive schemas, thus broadening knowledge and understanding (Drew \& Mackie, 2011; Powell \& Kalina, 2009). When applied to the classroom, active learning pedagogical strategies go beyond the traditional delivery of lecturing on the part of the instructor by engaging students through interactive activities where they can apply what they have learned (Berry, 2008). Lundahl (2008) noted that deeper-level learning occurs when students are directly involved with the material.

Watkins, Carnell, and Lodge (2007) define active learning as having three components. The first is behavioral, where students are engaged in instructor-created activities; the second is cognitive, where students are engaged in critical thinking and decision-making, thus making use of critical thinking skills; and the third component is social, as students engage with each other. Building upon the work of Watkins et al.(2007), Drew and Mackie (2011) added affect as a fourth component, drawing on the classic model of Bloom's taxonomy (1965) that recognizes students' motivational capacity in the affective domain. This implies the importance of the instructor's role or presence in explicating the pertinence of the content for students and creating an environment in which students want to learn. It also suggests that instructors need to be attentive to students' anxiety towards the content, as well as the format of the course. 


\section{Instructor Presence}

Instructor presence, as described by Garrison, Anderson, and Archer (2000), involves instructors facilitating course flow and content, encouraging student participation, directly interacting with students, providing timely responses to questions, and promoting involvement with discussion questions. Studies suggest that the instructor is essential to the learning community and have found learning outcomes directly tied to active instructor presence in the course (Picciano, 2002; Swan \& Shih, 2005). Interaction with instructors has been found to have a strong positive effect on satisfaction and learning (Swan, 2001). Boettcher and Conrad (2010) go as far as proposing that instructor presence is one of the most important practices for online teaching.

Most educators strive to reduce students' anxiety and enhance learning outcomes but are not sure which strategies can accomplish these goals (Schacht \& Stewart, 1990). This is especially true for courses such as research methods, which is not easily taught in an online format. Several studies found success in teaching traditional social work research courses with active learning strategies (Barrakat, 2005; Marek, Christopher, \& Walker, 2004; Walsh, 1998), but little has been reported for online courses. Currently, there is scant evidence regarding what specific teaching strategies assist in reducing research anxiety and augmenting research knowledge, especially in online social work research courses.

This exploratory study begins to fill some gaps in this area by seeking to answer the following: a) What online teaching strategies are effective for decreasing students' anxiety? b) What online teaching strategies are effective for increasing students' perception of acquiring research knowledge?

\section{Methods}

\section{Research Methods Course}

This study was conducted at a liberal arts university with an online MSW program. All students take online courses which include a variation of synchronous and asynchronous components. The foundation level research methods course was delivered online over 16 weeks and included both synchronous and asynchronous formats. Synchronous sessions were held each week for 90 minutes and were delivered using the Blackboard Collaborate platform where the instructor and students interacted via audio and webcam. Complementing the webcam sessions, the asynchronous platform was delivered using Learning Studio. Weekly modules were listed in tandem with the syllabus, outlining tasks for students to complete independently (e.g., assigned readings and homework) or with each other (e.g., discussion questions and online exercises). Each week students were expected to complete the asynchronous activities (via the Learning Studio site), and to read and prepare for the live Blackboard Collaborate sessions. Synchronous class sessions included review of the content and active learning strategies relating to the three components indicated by Watkins et al. (2007): behavioral components (e.g., games promoting knowledge and understanding), cognitive components (e.g. application exercises), and social components (e.g., group activities where students worked together in small groups). Asynchronous delivery also included the three components, such as voiced- 
over PowerPoint lectures, discussion questions, and homework assignments. Weekly announcements and email within the class were also used. Additional contacts with instructors were made through phone calls, emails, and/ or online individual meetings with students who requested assistance. Eight sections of the course were taught by four different instructors, with approximately 12 students in each section. To remain consistent, all sections used the same syllabus, book, format, and course materials. However, each instructor decided on the degree to which they used phone calls, emails, and meetings via webcam.

\section{Procedures}

Upon approval of the university Institutional Review Board (IRB), an email was sent at the end of the semester to all students $(\mathrm{N}=105)$ enrolled in the eight sections of the course during the fall and spring semesters. The email explained the study procedures and invited students to participate. It also included an implied consent form with a hyperlink to the survey. The web-based survey was administered via the secure Qualtrics website, which ensures that data remain private and encrypted. Students chose to participate by clicking on the hyperlink in the invitation email or in two subsequent reminders. The students were ensured that the survey was in no way related to their course work or grade. The voluntary and anonymous survey was offered to students at the end of the course. They were asked to rate their level of anxiety and their perception of research knowledge before and after the course.

\section{Design}

MSW students who completed the research methods course were invited to participate in a voluntary, anonymous, online survey. A posttest only design was used at the end of the fall 2013 and spring 2014 semesters to determine students' perceptions of which online teaching strategies were effective for decreasing their anxiety and increasing their research knowledge.

\section{Measures}

The researcher-created measure asked students to rate their level of anxiety as well as their level of perceived research knowledge before and after the course. They were also asked to rate the effectiveness of teaching strategies in reducing their anxiety and increasing their perception of research knowledge separately. The measure consisted of 20 items with ten focusing on anxiety and ten focusing on knowledge using a Likert-type scale (see Appendix). An example question was, "Prior to the beginning of the course, how would you rate your level of anxiety about Social work research methods?" Students responded on scale ranging from 1 (Not anxious at all) to 5 (Extremely anxious). Another example included, "How helpful were the online discussion questions on Learning Studio in increasing your knowledge of social work research methods?" Students responded on a scale ranging from 1 (They caused more confusion) to 5 (Extremely helpful).

To test the internal reliability of the measure, a Cronbach's alpha was calculated for the ten items regarding anxiety and separately for the ten items regarding knowledge. The 
results for both tests were $\alpha=0.82$, which suggests good internal consistency of the measure (Tavakol \& Dennick, 2011).

\section{Analytic Plan}

Descriptive analysis and paired sample t-tests were used to compare differences in students' reported anxiety and knowledge. Forty-three students completed the survey over two semesters for a response rate of $41 \%$. According to Sue and Ritter (2007), email surveys generally have response rates between $27-71 \%$, indicating this response rate to be typical.

\section{Results}

The analysis of the survey results indicated a significant difference between students' pre- and posttest perception of knowledge $t(43)=14.05, p<0.001$ and pre and post levels of anxiety $t(43)=6.47, p<0.001$, with knowledge increasing and anxiety decreasing by the end of the course. The effect sizes, as determined by Cohen's $d$ for paired measures, were 0.91 for knowledge and 0.71 for anxiety (see Table 1).

Table 1. Descriptive Statistics for Students' Knowledge and Anxiety and T-Tests of PrePost Differences with Effect Sizes

\begin{tabular}{lcccccc}
\hline & $\frac{\text { Pretest }}{\mathbf{M}(\mathbf{S D})}$ & $\frac{\underline{P o s t t e s t}}{\mathbf{M}(\mathbf{S D})}$ & $\underline{\boldsymbol{t}}$ & $\frac{\boldsymbol{d} f}{42}$ & $\underline{\boldsymbol{p}}$ & $\underline{\underline{\boldsymbol{d}}}$ \\
$\begin{array}{l}\text { Perception of } \\
\text { Knowledge }\end{array}$ & $1.93(0.68)$ & $3.38(0.54)$ & 14.049 & & & \\
$\begin{array}{l}\text { Anxiety } \\
\mathrm{p}<.01^{* *}\end{array}$ & $3(1.22)$ & $1.91(0.65)$ & 6.465 & 42 & $<.001^{* *}$ & 0.91 \\
\hline
\end{tabular}

The effectiveness of the various teaching strategies were indicated by students' mean ratings. All of the strategies were rated as more than moderately helpful with some having greater impact than others. The same three strategies were rated as the most helpful by students for both increasing perception of knowledge and reducing their: personal contact with the instructor either via email, phone, and/or online meetings $(M=4.37 ; M=4.40)$; the instructor's synchronous class sessions $(M=4.28 ; M=4.16)$; and active learning strategies employed during the synchronous class sessions (i.e., games, exercises, discussions, cases, etc.; $M=4.05 ; M=3.72)$. The strategies rated the least helpful by students in both increasing perception of knowledge and reducing their anxiety were homework assignments $(M=3.53$; $M=3.23)$, the online voice-over PowerPoint lectures $(M=3.57 ; M=3.29)$, and online discussion questions ( $M=3.56 ; M=3.33)$. The textbook was rated as helpful for learning but less helpful for reducing students' anxiety $(M=3.79 ; M=3.26)$. See Table 2 for the complete results. 
Table 2. Student Ratings of the Effectiveness of Teaching Strategies for Increasing Knowledge and Reducing Anxiety $(n=43)$

\begin{tabular}{lcc}
\hline & $\frac{\text { Knowledge }}{\boldsymbol{M}(\boldsymbol{S D})}$ & $\frac{\text { Anxiety }}{\boldsymbol{M}(\boldsymbol{S D})}$ \\
Contact with the professor & $4.37(0.95)$ & $4.40(0.85)$ \\
Synchronous class session & $4.28(0.80)$ & $4.16(0.89)$ \\
Synchronous activities (games, discussions, etc.) & $4.05(0.87)$ & $3.72(0.91)$ \\
Weekly announcements & $3.81(0.71)$ & $3.63(0.88)$ \\
Discussion questions & $3.56(0.88)$ & $3.33(0.94)$ \\
Textbook & $3.79(0.71)$ & $3.26(0.96)$ \\
Online Power Point lectures & $3.57(0.91)$ & $3.29(0.84)$ \\
Homework assignments & $3.53(0.85)$ & $3.23(0.83)$ \\
\hline Note: Each item was rated on a 5-point scale in which 1=Caused more & \\
confusion/anxiety and 5=Extremely helpful. & \\
\hline
\end{tabular}

\section{Discussion}

Overall, the results were positive for this course, as students' anxiety decreased and their perception of research knowledge increased by the end of the course. The findings were similar to Picciano (2002) and Swan and Shih (2005) who found students' anxiety and knowledge attainment were negatively correlated. This is not surprising as most people feel less anxious learning content with which they have some familiarity. This study confirms that student anxiety is a crucial variable which must be considered when teaching research methods courses, especially in an online format where direct contact is limited and students must perform some activities independently. It is interesting that the same three teaching strategies were responsible for reducing anxiety and increasing perception of knowledge in the students' views but not surprising that all three strategies were active learning strategies and/or involved the instructor. This is especially compelling since not all students had the same instructor for the course or took it during the same semester. Likewise, the strategies rated as least helpful were less interactive.

On average, students rated all of the teaching strategies used in the course as effective ( 3 or above) however, students still need contact from the instructor, even at the graduate level of education. While active pedagogical strategies require a change in the instructor's approach to teaching so as to include behavioral, cognitive, and social learning opportunities, there is also an implication that the students must also shift their understanding of learner as receiver of information to active and independent participant. Future studies should consider the concept of students' independence or need for validation and how it relates to anxiety and learning.

The results suggest that instructors' involvement and connection with students is essential. Instructor presence in the online environment can be created in ways other than physical presence and ways that increase students' independence. This is particularly important in the asynchronous environment where there is no direct contact with the instructor. 


\section{Limitations}

There were several limitations to this study. The first is that anxiety was self-reported and both pre- and post-data were gathered at the end of the course. This means that students were asked to remember how anxious they were several months earlier, which can result in inaccurate responses. Another primary concern is that students were asked to rate their perception of knowledge gained, as opposed to using actual course or test grades. In addition, there is a small sample size and lack of a comparison group, thus generalization of our findings is limited. The study is also limited by the use of multiple instructors in the courses and study. Although all were using the same syllabus, course materials, and teaching approach, there is no way to standardize human educators, or control for the instructor in an anonymous survey. The results should be interpreted as exploratory and should be considered as beginning knowledge to initiate more studies regarding the effectiveness of online teaching strategies. Future studies should consider using a traditional pre- and posttest, using course or test grades as a measure of knowledge, having a comparison group, and possibly using a standardized anxiety measure that allows for more objective data on anxiety levels. Students' learning independently from sources other than the instructor should also be assessed.

\section{Implications and Conclusions}

This preliminary study maintains that research methods courses continue to be anxietyprovoking for social work students. However, educators' use of the various components (i.e., behavioral, cognitive, and social) of active learning teaching strategies can assist in reducing anxiety and increasing students' knowledge of research, especially for courses taught in an online format. In addition, instructors' frequent engagement with students could help facilitate learning and reduce anxiety. Some suggestions include short voice messages or video clips for announcements in asynchronous environments.

In addition, educators may help students change their beliefs about learning away from a receptor or passive learner to an independent and active participant by assigning activities that facilitate learning apart from the instructor. For instance, activities that can be added include small group projects and peer interactions/exercises which then allow for instructors' positive and frequent feedback individually to students. Scaffolding (Hammond \& Gibbons, 2005) is another instructional strategy which assists in strengthening confidence as students slowly build their knowledge and skills as the content progressively increases in difficulty.

Online learning has reduced many logistical hassles and availed educational opportunities to many students who may not have been able to complete traditional class formats. However, learning is not necessarily easier or less anxiety-provoking online, and classes require well-planned strategies by both instructors and students for success. Whether education occurs in a face-to-face format or online, the instructor is still responsible for understanding where each student is situated and integrating strategies that reach them. So that learning may occur, educators are still responsible for reducing barriers (e.g., anxiety) and for being present in the learning of each student. For their part, online students are responsible for active engagement with the course material, their peers, and 
their instructor. Further research is needed to specifically address how to create and manage challenging online courses like research methods in graduate-level social work programs.

\section{References}

Barraket, J. (2005). Teaching research method using a student-centered approach? Critical reflections on practice. Journal of University Teaching and Learning Practice, 2, 65-74.

Berry, W. (2008). Surviving lecture: A pedagogical alternative. College Teaching, 56(3), 149-153. doi: http://dx.doi.org/10.3200/CTCH.56.3.149-153

Bloom, B. (Ed.). (1965). Taxonomy of educational objectives-The classification of educational goals/Handbook I: Cognitive domain. New York, NY: David McKay Company, Inc.

Boettcher, J. V., \& Conrad, R. (2010). The online teaching survival guide: Simple and practical pedagogical tips. San Francisco, CA: Jossey-Bass.

Bonwell, C. C., \& Eison, J. A. (1991). Active learning: Creating excitement in the classroom. 1991 ASHE-ERIC Higher Education Reports. ERIC Clearinghouse on Higher Education, The George Washington University, One Dupont Circle, Suite 630, Washington, DC 20036-1183.

Castaño-Muñoz, J., Duart, J., \& Sancho-Vinuesa, T. (2014). The Internet in face-to-face higher education: Can interactive learning improve academic achievement? British Journal of Education Technology, 45(1), 149-159. doi: http://dx.doi.org/10.1111/bjet.12007

Chan, A., \& Lee, M. (2005). An MP3 a day keeps the worries away: Exploring the use of podcasting to address preconceptions and alleviate pre-class anxiety amongst undergraduate information technology students. In D. Spennemann \& L. Burr (Eds.), Good practice in practice. Proceedings of the Student Experience Conference (pp. 59-71). Wagga Wagga, NSW: Charles Stuart University.

DeVaney, T. (2010). Anxiety and attitude of graduate students in on-campus vs. online statistics courses. Journal of Statistics Education, 18(1), 1-15.

Drew, V., \& Mackie, L. (2011). Extending the constructs of active learning: Implications for teachers' pedagogy and practice. The Curriculum Journal, 22(4), 451-467. doi: http://dx.doi.org/10.1080/09585176.2011.627204

Freeman, S., Eddy, S. L., McDonough, M., Smith, M. K., Okoroafor, N., Jordt, H., \& Wenderoth, M. P. (2014). Active learning increases student performance in science, engineering, and mathematics. Proceedings of the National Academy of Sciences, 111(23), 8410-8415. doi: http://dx.doi.org/10.1073/pnas.1319030111

Gal, I., \& Ginsberg, L. (1993). Feeling uncertain about uncertain things: The role of beliefs and attitudes in learning statistics. Proceedings on the Section of Statistical Education (pp. 29-38). Alexandria, VA: American Statistical Association. 
Garrison, D. R., Anderson, T., \& Archer, W. (2000). Critical inquiry in a text-based environment: Computer conferencing in higher education. The Internet and Higher Education, 2(2-3), 87-105. doi: http://dx.doi.org/10.1016/S1096-7516(00)00016-6

Green, R., Bretzin, A., Leininger, C., \& Stauffer, R. (2001). Research learning attributes of graduate students in social work, psychology, and business. Journal of Social Work Education, 37, 333-341. Sydney, Australia: National Centre for English Language Teaching and Research.

Hammond, J., \& Gibbons, P. (2005) What is scaffolding? In A. Burns \& H. de Silva Joyce (Eds.), Teachers' voices 8: Explicitly supporting reading and writing in the classroom (pp. 8-16).

Jaramillo, J. (1996). Vygotsky's sociocultural theory and contributions to the development of constructivist curriculum. Education, 117(1), 133-140.

Jiao, Q., Onwuegbuzie, A., \& Waytowich, V. (2008). The relationship between citation errors and library anxiety: An empirical study of doctoral students in education. Information Processing \& Management, 44(2), 948-956. doi: http://dx.doi.org/10.1016/j.ipm.2007.05.007

Lefmann, T., \& Combs-Orme, T. (2013). Early brain development for social work practice: Integrating neuroscience with Piaget's Theory of Cognitive Development. Journal of Human Behavior in the Social Environment, 5(23), 640-647. doi: http://dx.doi.org/10.1080/10911359.2013.775936

Lundahl, B. (2008). Teaching research methodology through active learning. Journal of Teaching in Social Work, 28(1-2), 273-288. doi: http://dx.doi.org/10.1080/08841230802179373

Marek, P., Christopher, A., \& Walker, B. (2004). Learning by doing: Research methods with a theme. Teaching of Psychology, 31, 128-131.

Picciano, A. G. (2002). Beyond student perceptions: Issues of interaction, presence, and performance in an online course. Journal of Asynchronous Learning Networks, 6(1), 21-38.

Powell, K. C., \& Kalina, C. J. (2009). Cognitive and social constructivism: Developing tools for an effective classroom. Education, 130(2), 241-250.

Ramsden, P. (1992). Learning to teach in higher education. New York: Routledge. doi: http://dx.doi.org/10.4324/9780203413937

Schacht, S., \& Stewart, B. (1990). What's funny about statistics? A technique for reducing student anxiety. Teaching Sociology, 18(1), 52-56. doi: http://dx.doi.org/10.2307/1318231

Schulze, S. (2009). Teaching research methods in a distance education context: Concerns and challenges. South African Journal of Higher Education, 23(5), 992-1008. doi: http://dx.doi.org/10.4314/sajhe.v23i5.48812

Sue, V., \& Ritter, L. (2007). Conducting online surveys. Thousand Oaks, CA: Sage. 
Swan, K. (2001). Virtual interaction: Design factors affecting student satisfaction and perceived learning in asynchronous online courses. Distance Education, 22(2), 306331. doi: http://dx.doi.org/10.1080/0158791010220208

Swan, K., \& Shih, L. (2005). On the nature and development of social presence in online course discussions. Journal of Asynchronous Learning Networks, 9(3), 115-136.

Tavakol, M., \& Dennick, R. (2011). Making sense of Cronbach's alpha. International Journal of Medical Education, 2, 53-55. doi: http://dx.doi.org/10.5116/ijme.4dfb.8dfd

Tsai, I.-C. (2012). Understanding social nature of an online community of practice for learning to teach. Educational Technology \& Society, 15(2), 271-285.

Walsh, J. (1998). A model for integrating research, practice, and field instruction in the undergraduate curriculum. Journal of Teaching Social Work, 17, 49-63. doi: http://dx.doi.org/10.1300/J067v17n01_05

Watkins, C., Carnell, E., \& Lodge, C. (2007). Effective learning in classrooms. London: Sage. doi: http://dx.doi.org/10.4135/9781446211472

Xu, D., \& Jaggars, S. (2014). Performance gaps between online and face-to-face courses: Differences across types of students and academic subject areas. The Journal of Higher Education, 85(5), 633-659. doi: http://dx.doi.org/10.1353/jhe.2014.0028

\section{Author note}

Address correspondence to: Lisa Rapp-McCall, Graduate Social Work program, Saint Leo University, P.O. Box 6665, Saint Leo, FL 33574-6665, lisa.rapp-

mccall@saintleo.edu 


\section{Appendix}

1. Prior to the beginning of the course, how would you rate your level of anxiety about Social work research methods?
$0 \quad$ Not anxious at all
o A little anxious
o Anxious
o Very anxious
o Extremely anxious

2. Prior to the beginning of the course, how would you rate your knowledge of Social work research methods?
o Not knowledgeable at all
o Some knowledge
o Moderately knowledgeable
o Very knowledgeable
o Extremely knowledgeable

3. How helpful were the online PowerPoint lectures on Learning Studio in increasing your understanding of Social work research methods?
o They caused more confusion
o Not helpful
o Moderately helpful
o Very helpful
o Extremely helpful

4. How helpful were the online PowerPoint lectures on Learning Studio in decreasing your anxiety about Social work research methods?

o They caused more anxiety

o Not helpful

o Moderately helpful

o Very helpful

o Extremely helpful

5. How helpful was the review of course content by the Professor on Collaborate in increasing your understanding of Social work research methods?
o It caused more confusion
o Not helpful
o Moderately helpful
o Very helpful
o Extremely helpful

6. How helpful was the review of course content by the Professor on Collaborate in decreasing your anxiety about Social work research methods? 

o It caused more anxiety
o Not helpful
o Moderately helpful
o Very helpful
o Extremely helpful

7. How helpful were the active Collaborate activities (cases, games, discussions, exercises) in increasing your knowledge of Social work research methods?

o It caused more confusion

o Not helpful

o Moderately helpful

o Very helpful

o Extremely helpful

8. How helpful were the active Collaborate activities (cases, games, discussions, exercises) in decreasing your anxiety of Social work research methods?

o It caused more anxiety

o Not helpful

o Moderately helpful

o Very helpful

o Extremely helpful

9. How helpful was the textbook in increasing your knowledge in Social work research methods?
o It caused more confusion
o Not helpful
o Moderately helpful
o Very helpful
o Extremely helpful

10. How helpful was the textbook in decreasing your anxiety about Social work research methods?
o It caused more anxiety
o Not helpful
o Moderately helpful
o Very helpful
o Extremely helpful

11. How helpful were the weekly announcements on Learning Studio from the Professor in increasing your knowledge of Social work research methods?

o They caused more confusion

o Not helpful

o Moderately helpful 
o Very helpful

o Extremely helpful

12. How helpful were the weekly announcements on Learning Studio from the Professor in decreasing your anxiety about Social work research methods?
o They caused more anxiety
o Not helpful
o Moderately helpful
o Very helpful
o Extremely helpful

13. How helpful were the online Discussion questions on Learning Studio in increasing your knowledge in Social work research methods?
0 They caused more confusion
o Not helpful
o Moderately helpful
o Very helpful
o Extremely helpful

14. How helpful were the online Discussion questions on Learning Studio in decreasing your anxiety about Social work research methods?
o They caused more anxiety
o Not helpful
o Moderately helpful
o Very helpful
o Extremely helpful

15. How helpful were the Learning Studio exercises in increasing your knowledge of Social work research methods?
o They caused more confusion
o Not helpful
o Moderately helpful
o Very helpful
o Extremely helpful

16. How helpful were the Learning Studio exercises in decreasing your anxiety about Social work research methods?
0 They caused more anxiety
o Not helpful
o Moderately helpful
o Very helpful
o Extremely helpful 
17. How helpful was the personal contact you had with the Professor (phone call, email, Collaborate) in increasing your knowledge in Social work research methods?

o It caused more confusion

o Not helpful

o Moderately helpful

o Very helpful

o Extremely helpful

o N/A

18. How helpful was the personal contact you had with the Professor (phone call, email, Collaborate, skype) in decreasing your anxiety about Social work research methods?

o It caused more anxiety

o Not helpful

o Moderately helpful

o Very helpful

o Extremely helpful

o N/A

19. How would you rate your current knowledge of Social work research methods?
o Not knowledgeable at all
o Some knowledge
o Moderately knowledgeable
o Very knowledgeable
o Extremely knowledgeable

20. How would you rate your current level of anxiety about Social work research methods?
o Not anxious at all
o A little anxious
o Anxious
o Very anxious
o Extremely anxious 